\title{
Prediction equations for balance measured as sway speed by head tracking with eyes open and closed
}

\author{
Kaye H Kilburn, John C Thornton
}

\begin{abstract}
Objectives-To provide prediction equations for balance measured as sway speed, a population of randomly selected subjects was used as a model.

Methods-265 subjects were selected from voter registration rolls in Arizona and Louisiana, USA. For validation these predicted values were compared with observed values obtained from a second population in California, USA.

Results-Sway speed with eyes open as a natural logarithm was:

ln (open) $=-0.248333-0.009634 \times$ age $+0.000164 \times$ age $^{2}$

and sway speed with eyes closed was:

$\ln$ (closed) $=-0.585707-0.023074 \times$ age $+0.000315 \times$ age $^{2}+0.038496 \times$ height (cm)

Conclusions-The natural logarithm of balance with the eyes open was related to age by both linear and quadratic functions. Additionally with the eyes closed balance was dependent on height. These equations can be used to predict performance of groups being studied for effects of noise and chemicals. To define abnormality of individual subjects the predicted value plus $1 \cdot 5 \mathrm{SDs}$ could be used.
\end{abstract}

(Occup Environ Med 1995;52:544-546)

Keywords: head tracking; age coefficients; sway speed

A major limitation to the usefulness of neurobehavioural tests as applied to occupational or environmental studies is the absence of expected scores. The need is most acute for balance for which expected values do not exist. As tests for neurotoxic effects have broadened beyond Wechsler's adult intelligence scale (WAIS) and his memory scale ${ }^{12}$ and Halstead's battery, ${ }^{3}$ we now have performance tests such as sway speed, latency of the blink reflex, colour discrimination, and reaction time. This has created the need to predict group results and individual expectations for each test related to age, sex, body size, and other factors. Impairment of balance in elderly subjects is well known and group studies have shown increased areas of the figure encompassed by trunkal tracking. ${ }^{4}$ Increased lateral and anteroposterior-lateral motion in subjects older than 70 have been reported by tracking ${ }^{5}$ and by force platform. ${ }^{67}$ Balance, measured by rail walking and standing, is adversely affected by aging as well as increased weight, height, abdominal girth, and body fat. ${ }^{8}$ Predictive equations would be helpful in interpreting balance as they have been in pulmonary function tests to adjust expected values for height, age, and sex. ${ }^{9}$ Predicted values are useful in body composition studies. ${ }^{10}$ To use these balance tests with the greatest efficiency to recognise impairment in subjects exposed to noise ${ }^{11}$ or chemicals $^{12}$ the confidence intervals must be defined.

Recent development of a computerised head (trunk) tracking device permitted a field study of ironworkers in whom balance impairment was associated with hearing loss. ${ }^{11}$ Next we showed that head tracking and a force platform measure balance equivalently. ${ }^{12}$ Application of balance tests to chemically exposed and control subjects created the need for control norms particularly to evaluate the effect of age and other factors. A carefully selected unexposed population had balance measured to permit statistical modelling including development of prediction equations.

\section{Methods}

Two geographically separate groups were contacted through voter registration rolls, and volunteers were given a battery of neurophysiological and neuropsychological tests. Two hundred and sixty four subjects, 121 women and 143 men, were tested. Their results are reported as group A. A comparison group of 29 adults recruited from California, 17 men and 12 women (group B), were used to validate the equations. All subjects were screened by questionnaire to exclude those with possibly confounding exposures and medical conditions. The protocol was approved by the Human Studies Research Committee of the University of Southern California School of Medicine. All subjects gave written informed consent for the study. They were compensated for their time.

Balance was tested with a computerised head tracker (Neuro-Test, Florence, OR), which records the horizontal pathway and speed of movement of a point sound source mounted on the head by means of two microphones $36 \mathrm{~cm}$ apart on a tripod. ${ }^{11}$ The instrument has been previously shown to provide measurements equivalent to those from a force platform. ${ }^{12}$

Three 20 second trials each for speed of sway with eyes open and again with eyes closed were obtained in alternating order for each subject with a brief rest period between trials. The minimal value from the three trials

Avenue, 2025 Zonal

Angeles, CA 90033, USA.

Accepted 20 March 1995 
Descriptive statistics

\begin{tabular}{lc}
\hline & Mean (SI) range \\
\hline Group A (n=264) & $44(20,18-83)$ \\
Age & $168 \cdot 4(9 \cdot 5,135 \cdot 9-194 \cdot 3)$ \\
Height $(\mathrm{cm})$ & $0 \cdot 769(0 \cdot 190,0 \cdot 434-1 \cdot 470)$ \\
Sway speed: & $1 \cdot 202(0 \cdot 387,0 \cdot 563-2 \cdot 686)$ \\
$\quad$ Eyes open $(\mathrm{cm} / \mathrm{s})$ & $40(10,20-61)$ \\
$\quad$ Eyes closed $(\mathrm{cm} / \mathrm{s})$ & $172 \cdot 7(7 \cdot 6,152 \cdot 4-185 \cdot 4)$ \\
Group B (n = 29) & $0 \cdot 731(0 \cdot 158,0 \cdot 498-1 \cdot 242)$ \\
Age (y) & $1 \cdot 050(0 \cdot 231,0 \cdot 581-1 \cdot 633)$ \\
Height $(\mathrm{cm})$ & \\
Sway speed: & Eyes open $(\mathrm{cm} / \mathrm{s})$ \\
$\quad$ Eyes closed $(\mathrm{cm} / \mathrm{s})$ &
\end{tabular}

is reported as the natural logarithm of speed of sway in $\mathrm{cm} / \mathrm{s}$ with the eyes open, $\ln$ (open), and also with the eyes closed, ln (closed).

Data from the two groups of subjects were used to develop the regression equations for eyes open and closed. Data from the 264 subjects in group A were used to develop the regression equations. The data obtained from the 29 subjects in group B were used to validate the equations.

Multiple regression techniques were used to develop the regression equations for eyes open and closed as functions of age, height, weight, strength, educational level, and sex. The Box-Cox transformation was used to study the need to transform the dependent variable. ${ }^{13}$ Transformations of the independent variables, including products and powers, and interactions between variables were also considered. The models were evaluated with graphical methods to study residual plots. ${ }^{14}$ An influence analysis was performed to determine if there were any inconsistent data points. Cook's distance statistic was used as a measure of influence. ${ }^{13}$ A lack of fit test was performed on the final model with the $F$ statistic to compare the estimate of error obtained from replicates with the lack of fit component of the model's residual sum of squared error.

The final models were validated with the data from group B. The group B data were used to estimate the parameters of the model.

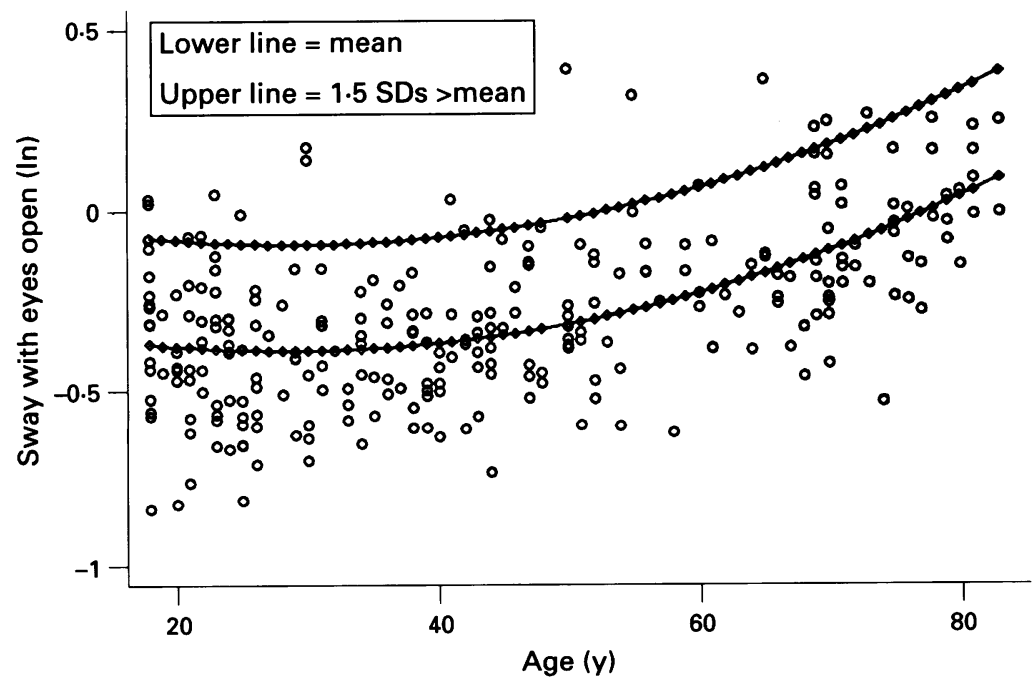

Plot of values of In (open) and age in individual subjects with the means connected (lower line). The upper line plots 1.5 SDs above the mean as a confidence interval to define the expected range.
An $F$ statistic was used to test the hypothesis that the parameter estimates obtained with group B data were equal to the parameter estimates of model.

\section{Results}

The 264 subjects in group A were between 18 and 82 years of age, had a mean sway speed with eyes open of $0.769 \mathrm{~cm} / \mathrm{s}$ and with eyes closed of $1.202 \mathrm{~cm} / \mathrm{s}$ (table). The 29 group B subjects were similar, with an eyes open speed of $0.731 \mathrm{~cm} / \mathrm{s}$ and with an eyes closed speed of $1.050 \mathrm{~cm} / \mathrm{s}$ (table).

The regression equation for sway speed with eyes open is:

$$
\begin{gathered}
\ln (\text { open })=- \\
0.248333-0.009634 \times \text { age }+ \\
0.000164 \times \text { age }^{2}
\end{gathered}
$$

where ln (open) is the natural logarithm of the speed with eyes open. The $r^{2}$ for the equation is 0.31 and the SD is 0.196 .

The regression equation for sway speed with eyes closed is:

$$
\begin{gathered}
\ln (\text { closed })=-0.585707-0.023074 \times \text { age }+ \\
0.00315 \times \text { age }^{2}+0.005967 \times \text { height }(\mathrm{cm})
\end{gathered}
$$

where $\ln$ (closed) is the natural logarithm of the speed with eyes closed. The $r^{2}$ for the equation is 0.32 and the $S D$ is 0.251 .

The validation procedure used the group $B$ data. The parameter estimates obtained were not significantly different from the parameter estimates obtained with the group $A$ data (open: $P=0.67$; closed: $P=0.78$ ). The equations predict mean sway speeds for group $\mathrm{B}$ of $0.70 \mathrm{~cm} / \mathrm{s}$ (open) and $1.03 \mathrm{~cm} / \mathrm{s}$ (closed). The observed mean sway speeds for group B were $0.73 \mathrm{~cm} / \mathrm{s}$ (open) and $1.05 \mathrm{~cm} / \mathrm{s}$ (closed).

\section{Discussion}

A head tracking procedure has been devised with a sound emitter on the head, two microphones, and a high sampling rate $(16 \cdot 7 / \mathrm{s})$ recorded by a microcomputer that has been used to measure balance. Of the variables analysed, speed of sway proved to be the most sensitive although distance was also usable. ${ }^{11}$ This procedure yielded consistently high repeatability of measurements compared with the conventional force platform, which used pairs of force transducers (foil deflection strain gauges) at the corners of a $110 \mathrm{~cm}$ square platform. The sampling rate of $4000 / \mathrm{s}$ was reduced to $60 / \mathrm{s}$ and reproducibility was within $2 \%{ }^{12}$ The population derived unexposed control group A, was used to develop a model that was validated with a second group $B$, the observed mean values of which were not different from those predicted. These prediction equations provide an immediate comparison for groups being evaluated for balance. The absence of other factors, especially sex and weight, simplify the consideration of balance in tests and make it easy to apply the prediction formulas for group comparisons.

For detecting individual differences from the expected values at ages 18 to 85 years the use of $1.5 \mathrm{SDs}$ above the predicted value of 
sway with eyes open and eyes closed seems reasonable (fig). Increases of sway speed above this range increased the likelihood of clinical abnormality (unpublished). The plot of the $\log$ of the speed of sway with eyes closed, which needed height as the third dimension looked similar but the resulting ovals or rectangles detracted from visualisation of the relation between balance and age.

Balance impairment accompanied hearing loss in iron workers exposed to noise. ${ }^{11}$ Balance was also impaired in workers exposed to lead, ${ }^{15}$ exposed to solvents, ${ }^{1617}$ and in populations residentially exposed to trichloroethylen $^{18}$ and polychlorinated biphenyls and trichloroethylene. ${ }^{19}$ Thus, balance measurement detects effects of exposure to chemicals with sensitivity. In each instance, control values had to be measured. These model equations although directly applicable to the head tracking method of measurement provide a comparison for other control groups as well as a means for tentatively deciding about the deviation from the expected for groups of subjects in pilot studies. To judge an individual subject's abnormality was previously difficult especially in older subjects because standards were lacking. ${ }^{21}$ This modelling of healthy people implies progressive impairment with age rather than effects of age related disease suggested recently..$^{21}$ These prediction equations provide a basis for making that judgment of balance and tentatively for comparing individual performance.

Wechsler D A standardized memory scale for clinical use. 7 Psychol 1945;19:87-95.

Wechsler D. Adult intelligence scale manual (revised). New York: Psychological Corporation, 1971
3 Halstead WC. Brain and intelligence: a quantitative study of the frontal lobes. Chicago: University of Chicago Press. 1947 .

4 Sheldon JH. The effect of age on the control of sway. Gerontologia Clinica 1963;5:129..38

5 Boman K, Jalavisto E. Standing steadiness in old and young persons. Annales Medizines Experimentals Biologica Fennae 1953;31:447-55.

6 Era P, Heikkinen E. Postural sway during standing and unexpected disturbance of balance in random samples of men of different ages. $\mathcal{F}$ Gerontology' 1985;40:287 95.

7 Thyssen HH, Brynskov J, Jansen EC, Munster-Swendsen $\mathrm{J}$. Normal ranges and reproducibility for the quantitative Romberg's test. Acta Neurol Scand 1982;66:100-4.

8 Fregly AR, Oberman A, Graybiel A, Mitchell RE Thousand aviator study: nonvestibular contributions to Thousand aviator study: nonvestibular contributions to postural

9 Morris JF, Koski A, Johnson LC. Spirometric standards for healthy nonsmoking adults. Am Rev Respir Dis 1971;103:57-67.

10 Bernstein RS, Thornton JC, Yang MU, Wang J, Redmond $\mathrm{AM}$, Pierson RN, et al. Prediction of the resting metabolic rate in obese patients. Am F Clin Nutr 1983;37 595-602.

11 Kilburn KH, Warshaw RH, Hanscom B. Are hearing and balance dysfunction linked in construction ironworkers. Br f Ind Med 1992;39:101-14.

12 Kilburn $\mathrm{KH}$, Warshaw RH, Hanscom B Balance measured by head (and trunk) tracking and a force platform in chemically (PCB and TCE) exposed and referent subjects. Occup Environ Med 1994;51:381-5.

13 Stata Corporation. Stata reference manual, release $3 \cdot 1$, vol 2. College Station, TX: Stata Corporation 1993: 77840

14 Hamilton LC. Regression with graphics, a second course in applied statistics. Pacific Grove, CA: Brooks and Cole. 1992

15 Schwartz J, Otto D. Lead and minor hearing impairment. Arch Environ Health 1991;46:228 -35.

16 Savolainen $\mathrm{K}$, Linnavuo $M$. Effects of $\mathrm{m}$-xylene on human equilibrium measured with a quantitative method. Acta equilibrium measured with a quantitative m
Pharmacologica et Toxicologica $1979 ; 44: 315-8$

17 Morata TC. Dunn DE, Kretschmer I,W, Lemasters GK. Santos UP. Effects of simultaneous exposure to noise and toluene on workers hearing and balance. and toluene on workers hearing

18 Kilburn KH, Warshaw RH. Effects on neurobehavioral performance of chronic exposure to chemically contaminated well water. Toxicol Ind Health 1993;9:391-404

19 Kilburn KH, Warshaw RH. Neurobehavioral testing of subjects exposed residentially to groundwater contamnated from an aluminum die-casting plant and local referents. 7 Toxicol Environ Health 1993;39:483-96.

20 Wolfson L. Whipple R. Derby CA, Amerman P. Murphy T. Tobin JN, Nashner L. A dynamic posturography study of balance in healthy elderly. Ncurologv 1992;42: $2069-75$. 


\section{BOOK REVIEW}

Book review editor: R L Maynard

If you wish to order, or require further information regarding the titles reviewed here, please write or telephone the BMJ Bookshop, PO Box 295, London WX1H 9TE. Tel: 0171383 6244. Fax: 0171383 6662. Books are supplied post free in the UK and for British Forces Posted Overseas addresses. Overseas customers should add $15 \%$ for postage and packing. Payment can be made by cheque in sterling drawn on a UK bank, or by credit card (MasterCard, VISA, or American Express) stating card number, expiry date, and your full name.

(The price and availability are occasionally subject to revision by the Publishers.)

Fitness For Work: The Medical Aspects. 2nd edition. Edited by COX RAF, EDWARDS FC, MCCALLUM RI. (Pp 518; price $£ 60$ (hardback).) 1995. Oxford: Oxford Medical Publications. ISBN 0-19-2623443 (Hbk) 0-19-2623451 (Pbk).

This is the second edition of a publication by the Faculty of Occupational Medicine of the Royal College of Physicians, first published in 1988, and launched at a Faculty conference in London in February this year. The Department of Social Security and Health and Safety Executive contributed to production costs. It is likely that most United Kingdom readers of this journal will be at least aware of its existence, if not actually own a copy.

There are relatively few jobs with clearly defined criteria for fitness. Experience has shown that judgements on employability vary widely among different practitioners, suggesting the need for better consistency in opinion. Restrictions on employability may be imposed unnecessarily and the individual denied opportunity to engage in their chosen job or progress in a career, with consequent frustration and socioeconomic disadvantage. Conversely, health risks from a particular type of job might be underestimated, or possibly not recognised at all, with potentially harmful consequences for the individual employee or others in the workplace. There is a clear need, therefore, for greater awareness of this subject-as well as a practical source of advice and reference on fitness issues for medical and nursing practitioners, managers, and others concerned with health in the workplace.

This particular book comes highly commended. It is highly readable at a lengthy sitting and also provides a helpful reference source to dip into as needed. It is crammed with information and advice based on the considerable experience of the many contributing authors. Much of the material is difficult to find in other publications. Each chapter is written as a joint item by an occupational physician and a practising clinician in the particular specialty or field of practice discussed. It deals with general principles underlying medical assessments for work, the interface between medicine and the workplace, legal aspects, ethical issues, and current services and provisions for those with disabilities. Significant new additions and updates add value to the first edition, including descriptions of spinal disorders, trauma, fitness for work overseas, ill health retirement, European Union legislation, and ethics. The text describes situations as diverse as a prospective diver with a healed, scarred tympanic membrane to the applicant for a public service vehicle licence who has a colour vision impairment (both of whom are likely to be fit for their chosen vocations).

The book reaffirms the continuing prejudice which is still shown in attitudes to the employment of people with health problems and disabilities. This may occur for a number of complex reasons, though in a practical sense it can reflect fear of poor sickness absence record, and the inconvenience and business costs which follow-a fear that is generally unfounded. The effect is to reduce the likelihood of employees disclosing conditions which might be better known to the employer-for example, for safety reasons if modification is needed to the job or environment.

Appropriate emphasis is given in the book to multidisciplinary cooperation as a requirement for the effective management of fitness issues in employment. There is mention too of the ever changing nature of the work environment, the introduction of new technologies and working practices, emergent risks to health, and other changes which may have beneficial as well as negative influences on employment prospects for those with health impairments.

Doctors in training for associate of the Faculty of Occupational Medicine, as well as more experienced specialists, will find much that is useful in this book. It will serve well the needs of practitioners in occupational health and primary health care; thereby, the beneficiaries will be the disabled themselves.

FRASER M KENNEDY

NOTICES

2nd International Health and Ecology Conference. 25-28 September 1996. University of Wollongong, New South Wales, Australia.

The host of this important event is Nursing the Environment; the Australian Nursing Federation National Special Interest Group.
The conference theme will explore the issues of community and work based initiatives, policy development, emergency ecological and theoretical perspectives for a healthy world and alternative models of health care. Three international keynote speakers have already accepted direct invitations to present. They are:

- Dr Ilona Kickbush-World Health Organisation, Switzerland

- Dr Eleanore Schuster-College of Nursing, Florida

- Professor A J McMichael-University of London

The target audience includes health care professionals, members of governments, businesses, industry, educational institutions and the community at large. We anticipate an attendance in excess of 400 delegates.

For further information contact: The Meeting Planners, 108 Church Street, Hawthorn, Victoria, Australia 3122. Phone (61 3) 9819 3700: Facsimile: (61 3) 9819 5978 .

Industrial Audiometry Courses. 20-22 March and 17-19 April 1996. Manchester.

These two identical three day courses offer training in audiometry for industrial medical staff, safety officers, and others concerned with hearing conservation in industry. The courses, which comply with the syllabus recommended by the British Society of Audiology have the approval of the Society. The courses will be held at the Wendover Hotel, Eccles, Manchester.

Full details are available from $\mathrm{Dr} W$ Tempest, "Kismet", Croyde Rd, St Annes, Lancs FY8 1EX. Tel (01253) 712550.

\section{CORRECTION}

Kilburn KH, Thornton JC. Prediction equations for balance measured as sway speed by head tracking with eyes open and closed (1995;52:544-6). The sway speed equation with eyes closed, in the abstract and results section, should be:

$\operatorname{Ln}($ closed $)=-0.585707-0.023074 \times$ age $+0.000315 \times$ age $^{2}+0.005967 \times$ height $(\mathrm{cm})$ 